\title{
A Educação em Direitos Humanos no Ensino de Ciências em interface com a teoria do Giro Decolonial: uma análise
}

\author{
Roberto Dalmo Varallo Lima de Oliveira ${ }^{1}$ \\ Stephanie Di Chiara Salgado ${ }^{2}$
}

\begin{abstract}
RESUMO
Este artigo busca estabelecer uma reflexão baseada na pergunta: O que há de decolonial nas propostas que relacionam Educação em Ciências e Direitos Humanos? Com base num estudo teórico, primeiro buscou-se apresentar o grupo Modernidade/ Colonialidade/ Decolonialidade (MCD). Em seguida, as propostas elaboradas por Oliveira e Queiroz (2013, 2015, 2017) acerca da Educação em Ciências na perspectiva da Educação em Direitos Humanos foram analisadas, apontando em quais sentidos elas convergiam ou divergiam das formulações teóricas decoloniais. A partir das análises tecidas, concluímos que há possíveis aproximações e diálogos entre estes campos, uma vez que as obras de Oliveira e Queiroz se posicionam politicamente ao lado daqueles que foram subalternizados e historicamente marginalizados, fomentando a construção de uma educação contra-hegêmonica e combativa. Em termos de afastamentos, os autores não confrontam diretamente o modelo de educação escolar, e esta seria uma das fronteiras a serem rompidas para uma prática decolonial.
\end{abstract}

PALAVRAS-CHAVE: Educação em Direitos Humanos. Decolonialidade. Ensino de Ciências.

Education in Human Rights and Teaching of Science in interface with Decolonial Turn's theory: an analysis.

\footnotetext{
${ }^{1}$ Doutor em Ciência, Tecnologia e Educação, professor da Universidade Federal do Paraná (UFPR), Paraná, PR, Brasil. https://orcid.org/0000-0002-8348-966X.robertodalmo7@gmail.com

${ }^{2}$ Mestranda em Educação, professora do Institudo Federal de Educação, Ciência e Tecnologia (IFRJ - Campus Pinheiral), Rio de Janeiro, RJ, Brasil. https://orcid.org/0000-0002-4299-5507. stephsalgado@ gmail.com
} 


\begin{abstract}
This article seeks to establish a reflection based on the question: Can we find decolonial principles in proposals that relate Education in Sciences with Human Rights? To do so, we first sought to present the Modernity / Coloniality / Decoloniality (MCD) group. Then, the proposals elaborated by Oliveira and Queiroz $(2013,2015,2017)$ on Education in Sciences from the perspective of Human Rights Education were analyzed, pointing out to which senses they have converged or diverged with the decolonial theoretical formulations. Based on the analyses, we conclude that there are possible dialogues to be established between fields at stake. Since the works of Oliveira and Queiroz stand politically alongside those who have been historically marginalized, fomenting the construction of a counterhegemonic education. Despite that, the authors do not directly confront the school education model, and this would be one of the frontiers to be broken for a decolonial practice.
\end{abstract}

KEYWORDS: Human Rigths Education. Decolonial turn. Science Education.

$$
* * *
$$

"La primera condición para cambiar la realidad consiste en conocerla". Eduardo Galeano - Las venas abiertas de América Latina.

\title{
Introdução
}

Quando pensamos em Direitos Humanos, de imediato, associamos à Declaração Universal dos Direitos Humanos e à Organização Nacional das Nações Unidas (ONU), que em 1948, foi assinada em Paris, na França, tendo-a como um grande marco na luta por melhores condições de vida e de dignidade humana. Logo em seguida, aqueles que são mais críticos nos fazem enxergar que essa mesma Declaração foi na verdade elaborada por um grupo de homens brancos, europeus e engravatados, que estabeleceram uma gramática de dignidade humana chamando-a de como "universal", ou seja, válida para todas e todos.

Mas, é no mínimo contraditório que tal Declaração tenha sido assinada prezando pela dignidade humana enquanto, apenas a título de 
exemplo, a própria França exercesse um enorme poder colonial sobre o território africano. Dessa forma, quando pensamos em Direitos Humanos, pensamos também em diversos processos colonizatórios e violentos. Nos perguntamos então, quem são os humanos de que se trata a Declaração Universal dos Direitos Humanos?

Surge então o desafio de pensarmos em Direitos Humanos a partir de um grupo de sujeitos mais diversos, e sobretudo, de pensar as relações de poder existentes já que os processos de humanização podem caminhar de mãos dadas com processos de desumanização, para então agir diante de uma realidade que muitas vezes se mostra cruel e injusta. Como caminho para intervenção nessa realidade complexa e contraditória surge a Educação em Direitos Humanos (EDH), com o intuito e a tarefa de alargar e ampliar o sentido dos Direitos Humanos.

No contexto latino-americano, segundo Silva e Tavares (2013), a EDH surge a partir das lutas de resistência contra o autoritarismo das ditaduras que se estabeleceram em um período entre meados da década de 1960 e final da década de 1980. Entretanto, apesar de em 1993 a EDH ter ganhado destaque na conferência sobre Direitos Humanos da ONU - garantindo a repercussão internacional dessa área, no Brasil, o tema só ganha destaque em 2003 com a criação do Comitê Nacional de Educação em Direitos Humanos (BRASIL, 2003). Na sequência, em 2006 houve o surgimento do Plano Nacional de Educação em Direitos Humanos - PNEDH (BRASIL, 2006). Anos depois, o Conselho Nacional de Educação aprovou as Diretrizes Nacionais para a Educação em Direitos Humanos (BRASIL, 2012), reforçando em seu artigo $4^{\circ}$ que a $\mathrm{EDH}$ possui como base a afirmação de valores, atitudes e práticas sociais que expressem a cultura dos direitos humanos em todos os espaços da sociedade e a formação de uma consciência cidadã capaz de se fazer presente nos níveis cognitivo, social, cultural e político.

Candau et al. (2013) apontam princípios importantes à EDH. Para as/os autoras/es é urgente estimular nas/os professoras/es a construção de 
um olhar que permita se indignar com as violações cotidianas, levando-as/os a uma atitude de enfrentamento. Esse princípio é destacado por Sacavino (2009) via pedagogia do empoderamento, processo que busca potencializar grupos ou indivíduos sociais que foram postos à margem historicamente. $\mathrm{O}$ princípio da formação de Sujeitos de Direito implica em desenvolver a percepção de que o direito, quando assegurado pelo Estado, foi ou ainda é fruto de muita luta daquelas/es que tiveram ou têm na atualidade sua humanidade violada. Ser sujeito de direitos implica em quatro movimentos: i) saber/conhecer os direitos; ii) desenvolver uma autoestima positiva; iii) desenvolver uma capacidade argumentativa; iv) promover uma cidadania ativa e participante.

Para o fortalecimento da democracia torna-se fundamental pensarmos a EDH como um "exercício da capacidade de indignação articulado ao direito à esperança e admiração da/pela vida, a partir do princípio de equidade que nasce da articulação dos princípios de igualdade e diferença” (CANDAU et al., 2013, p. 47). Um caminho para o estímulo da indignação seria a afirmação do "nunca mais", um princípio de recuperação histórico da memória e do esquecimento das violações de Direitos Humanos com a esperança de que elas não voltem a ocorrer.

Tendo em vista essa sequencia de políticas públicas, consideradas como um avanço para o campo progressista, se tornou urgente e importante que se estabelecesse tais discussões nos diversos âmbitos da formação de educadores no Brasil, e por isso mesmo, na Educação em Ciências. E tendo em vista a importância de alargar a concepção de humanização presente nos Direitos Humanos, tais discussões se propõem a refletir sobre "que direitos humanos é esse?" e “qual Educação em Direitos humanos é essa?". Ressaltamos ainda que, apesar de seu surgimento com base popular e antiditatorial na América Latina, e de um suposto consenso em torno dos DH durante a promeira década dos anos 2000, frente ao contexto político atual, muito pode ter se transformado. 
O presente artigo seguirá a trilha construída por Oliveira e Queiroz (2013), no sentido de alargar a concepção daquilo que se entende por Direitos Humanos e o que cabe neste conceito político, de forma que nos atrevemos a dar mais alguns passos - ainda na mesma direção, mas como numa espiral onde nunca se nega o ponto de partida e as inter-relações multidimensionais -, buscando fincar cada vez mais nossos pés no território Latino-Americano, porque já nos ensinara Frei Beto: "A cabeça pensa onde os pés pisam".

Sendo assim, esse é um ensaio teórico (DEMO, 1985) que buscou, a partir de revisão bibliográfica, articular as produções de Oliveira e Queiroz (2013, 2015 e 2017) sobre ensino de ciências na perspectiva da EDH às teorias latino-americanas dos estudos decoloniais. A pergunta que guia as reflexões desse artigo é: O que há de decolonial nas propostas de Oliveira e Queiroz $(2013,2015,2017)$ que relacionam Educação em Ciências e Direitos Humanos?

Para estabelecermos estas reflexões nos basearemos na análise das obras: i) "Educação em Ciências e Direitos Humanos: reflexão ação em/para uma sociedade plural" (OLIVEIRA; QUEIROZ, 2013); ii) "Olhares sobre a (in)diferença: formar-se professor de Ciências em uma perspectiva de Educação em Direitos Humanos" (OLIVEIRA; QUEIROZ, 2015); iii) "Conteúdos cordiais: química humanizada para uma escola sem mordaça" (OLIVEIRA; QUEIROZ, 2017).

Apesar dos autores suprecitados apresentarem uma produção mais vasta do que o recorte feito, a escolha de tais obras levou em consideração o fato destas serem publicações em formato de livros, buscando incidir nos currículos dos cursos de formação de professores de ciências - que a partir das Diretrizes Curriculares Nacionais para a Formação Inicial e Continuada dos profissionais do Magistério da Educação Básica (BRASIL, 2015) passa a constar a Educação em Direitos Humanos como elemento formativo obrigatório. 
Sendo assim, nas páginas adiante faremos uma breve apresentação ao campo dos estudos decoloniais a partir das reflexões do grupo Modernidade/Colonialidade. Em seguida, traremos as análises das obras selecionadas de Oliveira e Queiroz a partir do giro decolonial, para por fim, tecer algumas considerações acerca das aproximações e distanciamentos entre a perspectiva da EDH e a decolonialidade em busca de um ensino de ciências comprometido com a humanização.

\section{Uma breve introdução ao Giro Decolonial}

Para avançarmos nessa questão, é imperativo nos remeter ao grupo Modernidade/ Colonialidade/ Decolonialidade (MCD), que desde o final dos anos 90 se propõe a construir um projeto epistemológico, ético e político para o continente latino-americano, a partir de uma crítica à modernidade ocidental, que segundo a formulação teórica do grupo, é derivada da colonização das Américas, e consequentemente, da colonialidade. Desta mesma forma, só é necessário um projeto decolonial devido à modernidade e à colonialidade forjada com esta primeira - daí a indissociabilidade da tríade MCD, que constitui o nome do grupo ${ }^{3}$.

Apesar de semelhantes, os termos colonização, colonialismo e colonialidade guardam diferenças importantes entre si. A colonização trata da invasão, do domínio geográfico de determinada região, que gera 0 colonialismo - estabelecimento das relações de poder e dependência entre metrópoles e colônias, através do controle dos recursos e da mão de obra daquela região. O colonialismo foi desfeito com a independência dos territórios invadidos e usurpados (colônias), contudo a colonialidade ali perdura, pois ela se dá no plano intersubjetivo, através da introjeção do

\footnotetext{
${ }^{3} \mathrm{O}$ grupo se constituiu a partir de um coletivo pesquisadores e pensadores de diversas áreas do conhecimento, alocados em diversas universidades. Dentre seus expoentes estão Aníbal Quijano (sociólogo peruano), Arturo Escobar (antropólogo colombiano), Catherine Walsh (lingüista, socióloga e pedagoga americana, residente no Equador), Enrique Dussel (filósofo argentino), Boaventura de Sousa Santos (sociólogo português). O MCD deriva do Grupo de Estudos Subalternos Latino-Americanos, que se baseou no grupo de Estudos Subalternos Asiáticos, fundado na década de 80 com o movimento pós-colonial desde a independência das colônias Africanas e Asiáticas. A diferenciação do MCD se dá na radicalização epistêmica. Para Quijano, era preciso questionar o colonizador, e não seguir utilizando-o como referencial teórico, já que a proposta é de libertação, rompimento com os modos de ser e pensar cunhados pela modernidade.
} 
colonizador nos povos colonizados, o que Dussel vai chamar do encobrimento do outro - apagamento de tradições e identidades pela introjeção violenta dos costumes e modo de ser e viver do colonizador.

Nas palavras de Maldonado Torres,

a colonialidade se refere a um padrão de poder que emergiu como resultado do colonialismo moderno, mas em vez de estar limitado a uma relação formal de poder entre dois povos ou nações, se relaciona à forma como o trabalho, o conhecimento, a autoridade e as relações intersubjetivas se articulam entre si através do mercado capitalista mundial e da ideia de raça. Assim, apesar do colonialismo preceder a colonialidade, a colonialidade sobrevive ao colonialismo. (TORRES, 2017, p.131)

Assim, o colonialismo é mais do que uma imposição política, militar, jurídica ou administrativa. Ele se desdobra sobre a forma da colonialidade, chegando às raízes mais profundas de um povo e sobrevive apesar da descolonização ou da emancipação das colônias latino-americanas, asiáticas e africanas nos séculos XIX e XX.

Quijano (2005) formula o conceito de colonialidade do poder para referir-se a essa situação. Esta seria uma estrutura de dominação que submeteu, principalmente, a América Latina e a África, a partir da invasão de seus territórios e colonização, materializada através da criação do conceito de raça como critério de desumanização do outro.

É preciso que fique explícito: a expansão marítima dos ibéricos e a invasão das Américas iniciaram um novo capítulo da história das relações de poder entre povos dominantes e dominados a partir da racialização. Grosfoguel (2016) evidencia essa relação ao destrinchar os métodos de dominação impostos pelos espanhóis (cristãos) aos mouros (mulçumanos e judeus) na conquista da Andaluzia em 1492, logo antes da expedição de Cristóvão Colombo - cujo nome não é o de um homem, mas sim de um projeto, que em genovês significa cristianizador, colonizador (Todorov, 1982). 
Naquele contexto, a relação de poder se dava através da religião cristãos dominando por direito e superioridade, islâmicos. Com a chegada nas Américas e o encontro de um povo "sem religião", há uma transformação dramática de um sistema de poder baseado em diferenças religiosas para outro baseado em diferenças raciais. O "índio" constituiu a primeira identidade moderna. Com a escravização dos africanos, o racismo religioso foi complementado, ou dolorosamente substituído, pelo racismo de cor.

A referência aos indígenas como sujeitos sem religião os remove da categoria humana. A religião é universal entre os seres humanos. Entretanto, a alegada falta de religiosidade entre os nativos não é tomada inicialmente para indicar a própria falsidade da assertiva, mas, ao contrário, serve para afirmar a existência de sujeitos não completamente humanos no mundo. A assertiva de Colombo sobre a falta de religião dos povos indígenas introduz um novo significado antropológico para o termo. À luz do que vimos até aqui, se faz necessário adicionar que este significado antropológico também se conecta a um método bastante moderno de classificação dos seres humanos: o racial. Com uma única jogada, Colombo trouxe o discurso sobre religião do plano teológico para o plano da antropologia filosófica moderna, que distingue diferentes graus de humanidade através de identidades fixadas, posteriormente denominadas raças. (TORRES, 2008a, p. 217)

Daí a afirmação de que o racismo é fundante da sociedade brasileira. Ele se expressa violentamente há mais de 500 anos no território latinoamericano.

Para além da colonialidade do poder, cunhada na classificação racial e na consequente desumanização do outro não-europeu, a colonialidade se expressa também através colonialidade do saber, que determina os conhecimentos reconhecidos como científicos e válidos, em detrimento daqueles que são místicos e não válidos; e a colonialidade do ser, que se exerce por meio da inferiorização, subalternização e desumanização do 
outro, como consequência da invisibilidade do poder e do saber. Todas essas expressões de colonialidade estão associadas à violência colonial - processo de genocídio, epistemicídio e espoliação ao qual foram submetidos os povos e a natureza dos territórios colonizados.

A epistemologia eurocêntrica ocidental dominante, não admite nenhuma outra epistemologia como espaço de produção de pensamento crítico nem científico. (GROSFOGUEL, 2007, p. 35)

Sendo assim, Mignolo (2003) nos traz a reflexão de como a narrativa do desenvolvimento, do progresso, da modernidade europeia, na verdade, se construiu a partir de muitas outras narrativas silenciadas. O eurocentrismo nada mais é do que uma autoproclamação baseada na negação violenta e histórica de outras formas de racionalidade.

Como afirma o filósofo colombiano Santiago Castro-Gomez (2003), a filosofia cartesiana assume a epistemologia do ponto zero, ou seja, um ponto de vista que não assume a si mesmo como ponto de vista. (...) Qualquer conhecimento que pretenda partir do corpo político do conhecimento (Anzaldúa, 1987; Fanon, 2010) e chegar à geopolítica do conhecimento (Dussel, 1977), em oposição ao mito do conhecimento da egopolítica cartesiana, é visto como tendencioso, inválido, irrelevante, sem seriedade, parcial, isto é, como conhecimento inferior. (GROSFOGUEL, 2016, p.30)

Mas, o que isso tem a ver com a Educação escolar? Hoje, a hegemonia do pensamento europeu segue sendo perpetuada nos conteúdos ensinados em sala de aula, nos textos, autores e cientistas que compõem o cânone das nossas escolas e universidades (GROSFOGUEL, 2016) alimentando os processos de colonialidade. Já parou para pensar como temos aceitado um monte de fatos/práticas/ações sem questioná-las? Como se, desde sempre tivesse sido assim, e assim para sempre será. Mas quem estabeleceu isso?! Para quem se estabeleceu isso?! Com qual finalidade?! A decolonialidade trata exatamente de questionar o que tem sido assumido como padrão 
inquestionável. Trata de mostrar às custas de quê, de quem e do que, a universalização de certos padrões - e dos padrões considerados certos - foi cunhada.

$\mathrm{Na}$ educação, muitas práticas pedagógicas são danosas ao desenvolvimento integral de nossos estudantes, como a homogeinização dos tempos, métodos e processos de aprendizagem; a avaliação finalística em detrimento de uma avaliação processual etc.; e mesmo assim, as mudanças em nossa forma de pensar e agir ainda são raras (OCAÑA, 2017). E esta mesma análise poderia se estender às práticas políticas, sociais e econômicas que se estabeleceram em nosso território, tantas vezes injustas e desrespeitosas à garantia de dignidade humana. Por que seguimos reproduzindo-as? Por que seguimos perpetuando-as?

Você deve estar pensando: mas faço parte de todo um sistema, é preciso cumprir o currículo; no ensino médio, devemos também preparar para o ENEM e o acesso às universidades... Na vida política, somos só uma formiguinha frente aos poderosos que têm dinheiro e controlam o poder... Como mudar?

Frente à crise educação, mas também política, social, econômica e ambiental urge novas formas de pensar e agir, de se relacionar com o fazer político-pedagógico. Daí a necessidade de uma desobediência epistêmica (MIGNOLO, 2008), pois não poderemos fazer o novo, partindo do velho. É preciso, de acordo com os teóricos do grupo MCD, fazer um giro decolonial.

Isso significa que, a partir do pensamento do colonizador, não é possível libertar-se da colonialidade. Daí a importância para o grupo MCD de se pensar desde e com os condenados da terra ${ }^{4}$ e os oprimidos; desde e com os povos originários e de matrizes africanas; as mulheres, xs LGBTs. É preciso pensar a partir das margens, da periferia global. Por isso, este texto é também uma denúncia, mas que caminha para a busca de transformá-la em luta e anúncio de um inédito viável, como diria Freire, capaz de

\footnotetext{
${ }^{4}$ Termo que faz menção à obra "Os condenados da terra" de Franz Fanon, escritor martiniquenho envolvido na luta pela deslocolinização - territorial e mental - da África.
} 
transformar as condições de expropriação dos modos de ser, saber e existir dos povos não-europeus, ou seja, em nosso contexto, dos africanos em diáspora e dos povos originários da América Latina, que foram exterminados e encobertos pela colonialidade. É daí que trazemos a decolonialidade para o centro do nosso debate.

La descolonización que se propone cambiar el orden del mundo es un programa de desorden absoluto. Un proceso histórico aportado por nuevos hombres, un nuevo lenguaje, una nueva humanidad. (Frantz Fanon) $)^{5}$

É importante pontuar que o campo decolonial não fala de uma desqualificação do pensamento científico, mas visa evidenciar as relações de poder que foram fundantes da ciência moderna - processos como apagamento de saberes tradicionais e a hierarquização de conhecimentos, culminando no epistemicídio. Buscamos relacionar ciência e decolonialidade no sentido de desvelar como se deu a construção dos conhecimentos científicos e então combater as assimetrias de poder estabelecidas, buscando uma coexistência pautada nas questões culturais.

Segundo Ocaña (2017), Walsh assume e lidera as lutas decoloniais de nossa época ao propor múltiplas pedagogias decoloniais, refletindo sobre a Interculturalidade, o Estado e a Sociedade. A autora propõe práticas insurgentes de resistência, e fala sobre (re)existir e (re)viver na e desde a Abya-Yala - América Latina -, com e desde os condenados da terra, oprimidos, marginalizados, subalternizados, invisibilizados, silenciados, massacrados. É importante pontuar: o grupo MCD faz uma crítica voraz ao capitalismo como um sistema que impõe e reforça a geopolítica do conhecimento. Por isso mesmo, reconhecem a interculturalidade como a epistemologia, a política e a ideologia capaz de descolonizar a sociedade, o estado e o conhecimento.

\footnotetext{
${ }^{5}$ Frantz Fanon, Los condenados de la tierra. México: Fondo de Cultura Económica, 1961/2001, 30-3. In: WALSH, Catherine. Interculturalidad crítica y pedagogía de-colonial: apuestas (des)de el in-surgir, re-existir y re-vivir. Disponível em: rio.br/13582/13582.PDFXXvmi=di9ixOJob3xjBuscxZPZhgoEsplxlhlzBvSzkDZvGWP https://www.maxwell.vrac.puc-
} 
Contudo, de acordo com Catherine Walsh, hoje temos um trabalho ardiloso ao fazer tais denúncias e críticas, haja vista a inclusão das pautas dos grupos oprimidos, seja nos discursos públicos oficiais, seja nos discursos das instituições neoliberais, que seguem manipulando e cooptando movimentos, de formas cada vez mais sofisticadas e complexas. Não se pode negar que a inclusão dessas pautas é resultado das lutas travadas pelos movimentos sociais negros, indígenas, de mulheres, LGBTs e de minorias em geral, buscando atender suas demandas por reconhecimento e transformação social; contudo, não se deve perder de vista a perspectiva mercadológica de inclusão dessas pautas como o atendimento às demandas de mercado por novos públicos e uma política global pacificadora, que carrega em si uma lógica de poder e controle.

A autora explicita esta questão a partir da discussão sobre a polissemia do termo interculturalidade (WALSH, 2012). Esta que serve às demandas neoliberais foi categorizada enquanto uma interculturalidade funcional, onde cada ator social tem uma função, um papel, uma posição neste "tabuleiro social"; todos eles foram incluídos no jogo, e então basta jogar conforme as regras, entendendo a importância de cada peça. Veja que nesse sentido, as assimetrias de poder são constatadas, mas não combatidas.

A nós, oprimidos, nos interessa a valorização das diversas culturas e formas de ser, existir e se relacionar com a natureza; contudo, nos interessa mais ainda combater as assimetrias de poder - cunhadas desde o início da modernidade, em 1492, com a criação da ideia de raça, que nada tem a ver com aspectos biológicos, mas apenas subjetivos, usada para inferiorizar e desumanizar povos africanos e indígenas. Ou seja, nos interessa uma interculturalidade crítica. Por isso é preciso

hacer la distinción entre una interculturalidad que es funcional al sistema dominante, y ella concebida como proyecto político, social, epistémico y ético de transformación y decolonialidad. (...) la interculturalidad en si, solo tendrá significación, impacto y valor cuando está asumida de manera crítica, como acción, proyecto y 
proceso que procura intervenir en la refundación de las estructuras y ordenamientos de la sociedad que racializan, inferiorizan y deshumanizan, es decir en la matriz aún presente de la colonialidad de poder. (WALSH, 2012, p. 2)

Desde os anos 90, a temática da diversidade cultural, e propriamente o termo interculturalidade, esteve em alta nos documentos que pautavam as reformas curriculares e constitucionais latino-americanas - tomando como exemplo o Brasil, temos a "constituição cidadã" de 1988 e os parâmetros curriculares nacionais (PCN) de 1996. Nesses documentos, a valorização da diversidade cultural é umas das saídas apontadas para o enfrentamento aos preconceitos e estereótipos. Contudo, em relação aos PCN, inúmeras críticas são tecidas a este documento, tanto no sentido da baixa efetividade da política intercultural ali cunhada, quanto no sentido do atendimento às demandas do capital pela formação de mão de obra qualificada.

Nesse sentido é que considero necessário o questionamento aos Parâmetros Curriculares Nacionais para o Ensino Médio. Não apenas pelo fato de ser uma proposta curricular que se insere nas políticas de conhecimento oficial, que visam à homogeneidade cultural e o controle acentuado da educação, com base em princípios de mercado, estabelecidas na atualidade em países que assumem políticas neoliberais. Mas também porque, em seus princípios de organização curricular tão divulgados como representação do novo e do revolucionário no ensino, permanece uma orientação que desconsidera o entendimento do currículo como política cultural e ainda reduz seus princípios à inserção social e ao atendimento às demandas do mercado de trabalho. (LOPES, 2002, p. 396)

Hoje, quase vinte anos depois, poucos avanços se efetivaram no que diz respeito à inovação crítica das políticas curriculares. Em 2017, foi aprovada a Base Nacional Comum Curricular (BNCC), apesar da pouca participação dos setores populares e das críticas dos movimentos de 
educadores e da academia durante sua elaboração. Pode-se entender a BNCC como a consolidação de um processo de homogeneização e controle, de ratificação e disseminação do conhecimento eurocentrado, hegemônico e colonial, pelo menos no seu aspecto geral.

Nesse sentido, estudos abordam as insuficiências escolares na efetivação de uma educação que combata a matriz colonial de poder, apontando para os espaços não-formais que compõem o entorno das escolas, tais como os museus comunitários, terreiros e comunidades quilombolas, como ambiências promotoras de novas cartografias, com maiores condições de recomposição epistêmica e novas configurações dos processos de "reaprendizagens" (MIRANDA, 2013).

Miranda amplia a análise sobre as lutas por uma educação anticolonial ao reposicionar as fronteiras epistêmicas para além dos muros da escola, apontando que eles são um dos mais importantes obstáculos nos processos de descolonização do conhecimento. Isso porque é necessário construir com os excluídos historicamente e sistematicamente da sociedade, e por isso mesmo, também da escola.

Neste sentido, temos muito o que aprender com os povos que há 518 anos resistem e enfrentam os processos genocidas da colonização nas terras brasileiras: os indígenas e os afrodescendentes. Daí a importância da escola ampliar suas fronteiras e dialogar com esses povos. É a partir deles e com eles que podemos desaprender para então aprender uma outra lógica de ser, estar, viver e se relacionar. Do diálogo com eles e seu modo de vida poderão surgir inéditos viáveis, ou o que Valencia (2015 apud FLEURI, 2017, p. 283) aponta como uma perspectiva não-colonial.

O diálogo intercultural crítico com os povos originários implica em desconstruir os processos e princípios coloniais e em promover a construção de modos não-coloniais de ser e viver, bem como de poder e saber. Decolonializar implica um projeto intencional e processo contínuo e insurgente de diálogo e cooperação 
intercultural, que reinvente modos de vida não-coloniais." (FLEURI, 2017, p.284)

Para finalizar, é preciso dizer que o grupo MCD possui um vocabulário muito próprio, já que, como aponta Mignolo (2017), não devemos mudar apenas o conteúdo do discurso, mas também seus termos, sua forma - o que é reforçado pela linguista e pedagoga do grupo, Catherine Walsh.

Walsh nos esclarece que o prefixo "des”, em espanhol, tem uma conotação diferente do prefixo "de”. Descolonizar significa eliminar totalmente o colonial; é um resultado, um fim; em contrapartida, decolonizar significa ir diminuindo o colonial, atenuar, mitigar; não é um resultado, senão um processo. A partir deste ponto de vista, descolonizar não é o mesmo que decolonizar; tampouco descolonização é o mesmo que decolonialidade. A descolonização é a eliminação do colonial, e a decolonialidade é o fluir decolonial, a afluência até o não-colonial. (OCAÑA, 2017, p.23-24, tradução nossa)

Dialogando com Walsh e Ocaña, posicionamos aqui nossa opção pela terminologia "de" (decolonial/decolonialidade), pois entendemos que estamos num processo de construção deste horizonte utópico não-colonial e que não queremos iniciar uma nova epistemologia do ponto zero, mas sim combater os processos de epistemicídio já enunciados.

Ocaña (2017) nos apresenta dezenas de categorias fundantes do discurso decolonial, que são imprescindíveis para compreender a configuração da decolonialidade. Abaixo enumeramos alguns deles:

a) Colonialidad (Walter Mignolo); b) Colonialidad del poder (Aníbal Quijano); c) Colonialidad del saber (Edgardo Lander); d) Colonialidad del ser (Nelson Maldonado Torres); e) Decolonialidad (Catherine Walsh); f) Desobediencia epistémica (Walter Mignolo); g) Epistemicidio (Boaventura de Sousa Santos); h) Giro decolonial (Enrique Dussel); i) Giro epistémico decolonial (Ramón Grosfoguel); j) Hybris del Punto Cero (Santiago Castro-Gómez); k) 
Interculturalidad critica (Fidel Tubino)... (OCAÑA, 2017, p. 2021)

Sendo assim, a próxima sessão versará sobre o seguinte questionamento: seria possível que um grupo desenvolvesse uma produção teórico-prática decolonial, sem sabe-lo? Ou seja, sem utilizar estas categorias específicas?

\section{Educação em Ciências na perspectiva da EDH - um diálogo decolonial?}

A partir da reflexão sobre a decolonialidade, retomamos nossa pergunta: o que há de decolonial em propostas que relacionem Educação em Ciências e Direitos Humanos? Será que a obra de Oliveira e Queiroz (20113, 2015 e 2017), em suas publicações buscando pensar o ensino de ciências na perspectiva da educação em direitos humanos, convergem com os autores supracitados e contribuem para a consolidação de uma pedagogia decolonial desde o ensino de ciências, ou mesmo para a descolonização do ensino de ciências?

\section{i) Da prática à teoria}

A primeira questão que percebemos ser importante é que a relação entre Educação em Ciências e Direitos Humanos não surge, em nosso campo de trabalho como uma apropriação teórica seguida de uma tentativa de empreendimento prático, mas de forma inversa. É a prática, a experiência docente, os contextos conflituosos vividos em sala de aula que propiciaram a publicação do primeiro texto - "Educação em Ciências e Direitos Humanos: reflexão-ação em/para uma sociedade plural” (OLIVEIRA; QUEIROZ, 2013) - no intuito de denunciar o ocorrido em uma escola da Educação Básica em uma zona periférica do estado do Rio de Janeiro.

(...) em um único dia, presenciei inúmeros discursos de preconceito no ambiente escolar: discriminações contra homossexuais, negros, 
candomblecistas, umbandistas, ateus, judeus. Talvez nesse dia eu estivesse mais atento a essa questão. Talvez eu estivesse estudando mais sobre e, por isso, percebi com outro olhar aquilo que talvez fosse cotidiano e eu não havia observado até o momento. Uma enorme indignação surgiu e, não por acaso, nesse momento, percebi que falar de/em diversidade não é algo bem visto, e que há muitas escolas que se vendem como inovadoras, mas mantém discursos hegemônicos (OLIVEIRA; QUEIROZ, 2013, p.20)

Tal citação se refere ao momento no qual Oliveira, professor em questão, presencia violências simbólicas dirigidas a diversos grupos sociais, como LGBTs, negros e pessoas de religiosidades de matrizes não-cristãs. De acordo com sua narração, em um momento seguinte à percepção de tais opressões, foi elaborada uma aula para debater essas questões a partir do filme "O jardim de folhas sagradas", no qual o personagem principal era negro, bissexual e candomblecista. Após essa aula, o professor foi demitido, como relata no trecho: "O trabalho não foi concluído por "forças ocultas", a voz do professor foi calada e ele foi afastado de sua prática (...). Na semana seguinte ele foi convidado a não pertencer à equipe. Um cenário perverso de preconceito racial, disfarçado de intolerância religiosa foi o montado na escola em questão". (ibdem, 2013, p. 81)

Tais pontos dialogam com o esforço em se trazer a representatividade de minorias sociais para o ambiente escolar, mesmo que em formato discursivo e audiovisual, bem como as resistências que surgem dessa iniciativa. Aqui podemos visualizar mais concretamente o apontamento de Walsh que a interculturalidade em si não causa "problemas" - ninguém parecia ser contra, pelo menos explicitamente, à presença de negros, ou homossexuais, ou praticantes de religiões de matrizes africanas na escola -, afinal, viva à diferença! Mas, quando se busca combater e enfrentar assimetrias de poder socialmente construídas, conforme o professor buscou 
fazer ao trazer para o centro de sua aula aqueles que são marginalizados socialmente, aí já é demais.

Também é possível dialogar com as reflexões de Grosfoguel a respeito do epistemicídio e da perpetuação dos saberes europeus nos currículos ocidentais, como mecanismos da colonialidade. No texto, o autor traz para essa aula em questão o objetivo epistemológico de "Discutir as relações entre saberes populares e saberes científicos", utilizando como conteúdo abordado a "Bioquímica a partir das folhas do Candomblé", citando o artigo (MOREIRA; RODRIGUES FILHO; JACOBUCCI 2011), o que mostra a preocupação e a intenção de enfrentamento à referida eurocentralidade do conhecimento científico e do currículo escolar.

Os trechos destacados nos mostram a dificuldade de produzir práticas que visibilizem grupos historicamente marginalizados. E nos mostram também que tais sujeitos são os "sujeitos da colonialidade", ou seja, aqueles que foram e vêm sendo calados, encobertos e desumanizados pela violência colonial e pela colonialidade. Ao revelar as origens de tal marginalização histórica, a EDH caminha num sentido decolonial, pois se posiciona na luta anti-colonial.

Como pudemos analisar através da passagem descrita acima, este trabalho surgiu exatamente do enfrentamento ao processo colonial, mesmo não havendo sido interpretado desta forma naquele momento. Rapidamente, a violência colonial, hoje perpetuada através do racismo estrutural e da colonialidade, tratou de aniquilar a discussão, nos mostrando como a luta decolonial há que ser uma constante, e por isso, a Educação há que ser um caminho explicito para a humanização, entendendo que se comprometer com a humanização significa denunciar e combater os processos de desumanização.

\section{ii) Da teoria à prática}

Ao analisar o livro "Olhares sobre a (in)diferença: formar-se professor de ciências em uma perspectiva de educação em direitos humanos" 
percebemos que este foi dividido em três momentos. A "Parte I" destinada a uma abordagem teórica apresenta a uma centralidade na discussão sobre cultura:

Se cultura pode ser entendida como um modo de dar sentido ao mundo, uma forma de viver que é compartilhada por um grupo de pessoas, eu posso considerar que o machismo é uma cultura? Posso considerar a homofobia uma cultura? Posso considerar o racismo uma cultura? Sim. Ao trabalhar com direitos humanos buscamos também que essa representação de mundo seja mais válida do que as demais, ou seja, que a cultura dos direitos humanos seja considera superior à cultura das violações dos direitos humanos. Buscamos que o combate ao machismo torne-se mais relevante, como forma de dar sentido ao mundo, do que o machismo; buscamos que o combate à homofobia seja mais válido como "o bom", do que a homofobia; buscamos que o combate ao racismo seja uma cultura mais importante do que a cultura do racismo, etc. Só a partir de uma cultura de direitos humanos teremos um mundo que consiga dar mais voz àqueles que são subalternizados historicamente e fazer com que as violações que já aconteceram não voltem a ocorrer. (OLIVEIRA; QUEIROZ, p. 33 - grifo nosso)

$\mathrm{Na}$ citação acima, é possível perceber um compromisso com a modificação das estruturas via conflitos e não uma posição apaziguadora entre as diferenças. É perceptível um compromisso com o enfrentamento das desigualdades, principalmente no que diz respeito a questões raciais, de gênero e relacionadas à sexualidade, e o verbete "etc." deixa em aberto para muitos outros sujeitos e grupos.

Esse fragmento textual evidencia a interculturalidade crítica. Através da percepção de grupos e sujeitos subalternizados, faz um convite para que professores e professoras sejam parceiros no combate a essas formas de violência. Segundo Walsh (2012), a interculturalidade crítica é algo para se 
construir. A autora afirma a necessidade de mudar, não apenas as relações, mas as estruturas, condições e dispositivos de poder que mantém a desigualdade, a inferiorização, a racialização e a discriminação. Não é apenas tolerar ou incorporar as diferenças em uma matriz já estabelecida, mas refundar as estruturas sociais.

Outro ponto de destaque nessa produção é a importância dos movimentos sociais, presentes na Parte II, destinada a estabelecer relações entre a Educação em Direitos Humanos e a Educação em Ciências

Formar e formar-se como sujeito de direito implica na percepção de que o direito, quando assegurado pelo Estado, é fruto de muita luta daqueles que possuem sua humanidade violada. Assim, podemos elencar grupos de resistência e luta que expressam a voz de uma parcela da população - ONGs, Movimentos Sociais, grupos de defesa dos Direitos Humanos, entre outros coletivos.

A professora Maria da Glória Gohn, nos traz um entendimento dos movimentos sociais como ações sociais coletivas de caráter sociopolítico e cultural que viabilizam formas distintas da população se organizar e expressar suas demandas. Luta por direitos a partir de ações que se expressam através de denúncias, marchas, mobilizações, passeatas e, na atualidade, meios de comunicação midiáticos como as redes sociais. [...] Entender a luta nos movimentos sociais ajuda a compreender nossa posição enquanto ativos na busca pelos direitos sociais, civis, econômicos, ambientais, etc. (OLIVEIRA; QUEIROZ, p. 60-61)

O trecho em destaque traz relevância para o fato de que a formação de sujeitos de direito, uma das dimensões da EDH, se dá na luta, no embate, nas reivindicações populares daqueles grupos excluídos, marginalizados e oprimidos. Novamente, quando analisamos em nosso território quem são os 
grupos oprimidos, remontaremos às heranças coloniais. Ou seja, a luta por Direitos Humanos no sul global é a luta por descolonização.

O livro também tenta ser propositivo no trabalho com essas demandas provenientes de movimentos sociais, de forma que, na Parte III, são elaboradas oficinas que buscam estimular, na formação de professores/as de ciências, discussões sobre gênero e machismo, homofobia, saberes tradicionais e científicos, racismo, entre outros. Aqui é importante pontuar que tais propostas foram escritas por estudantes de licenciatura ou professores recém-formados. Ao abrir espaço para que alunos e/ou professores da Educação Básica escrevessem uma obra acadêmica, podemos entender que Oliveira e Queiroz dão passos na trilha da descolonização do conhecimento, pois enfrentam, mesmo que modestamente, o privilégio epistêmico - não são os "cânones", homens-brancos-europeus, que estão falando, trata-se de uma produção brasileira sobre o combate às formas de opressão presentes na nossa sociedade através do ensino de ciências.

Porém, nenhuma dessas oficinas traz diretamente, na sua elaboração, a colaboração desses grupos e sujeitos marginalizados, mas sim a teorização sobre eles, ponto que será trazido como importante diferencial na análise da próxima obra.

\section{iii) Propondo ressignificações para a prática}

Analisando a terceira obra selecionada, o livro "Conteúdos cordiais: química humanizada para uma escola sem mordaça” (OLIVEIRA; QUEROZ, 2017c), os autores nos convidam a repensar, ressignificar e humanizar o ensino dos conteúdos de química através do conceito de "ética da razão cordial" da filósofa espanhola Adela Cortina.

Cortina (2007) afirma que não é possível conhecer a justiça apenas pela racionalidade "pura", mas por uma razão que leve em consideração aspectos afetivos, como, por exemplo, a estima apreço, admiração, sentimento de carinho por alguém ou algo, e a compaixão - um sentimento piedoso de simpatia diante de algo 
ruim para a outra pessoa. A essa razão a autora deu o nome de "Cordial". Assim, tanto para a ética do discurso, quanto para a ética da razão cordial, o ponto central de nosso vínculo como humanos seria a comunicação. Entretanto, enquanto a ética do discurso estabelece nosso vínculo apenas no campo da argumentação, ou seja, em uma razão "pura”, a ética da razão cordial busca um sentido mais amplo de comunicação - onde há um entender comum e um sentir comum. (pág xxxi)

Trazendo sua aplicação aos conteúdos de química trabalhados numa Educação em Ciências na perspectiva da EDH, os autores acreditam que Apenas a razão pode nos levar a não perceber o outro-diferente e a não desenvolver capacidades como compaixão e estima, já o coração é formado por bases de diálogo e de mobilização de parceiros em um ideal de humanidade. É esse par, "razão e coração", que é central para a construção de uma visão de mundo que valorize os Direitos Humanos. Esses dois conceitos juntos podem contribuir para pensarmos uma escola que valorize a humanidade, e também para projetarmos uma aula de Química humanizada, que valorize a pluralidade e o diálogo. Esse par "razão e coração" nos ajuda a construir uma escola sem mordaças (...). (pág, xxix)

Como podemos perceber, a base teórica desde livro é eurocentrada, já que se inpira nas formulações da filósofa espanhola Adela Cortina. Contudo, gostaríamos de apresentar e analisar também seu sumário, abordando quais seriam esses chamados "conteúdos cordiais de química".

Capítulo 1 - Química das pimentas pelos caminhos de Exu; Capítulo 2 Mulheres de fibra: as quebradeiras de coco de babaçu e a reação orgânica de saponificação; Capítulo 3 - A Química das Funções Inorgânicas e o conflito das atividades mineradoras: história, trabalho e meio ambiente; Capítulo 4 - Aproximando gênero, ciências e teatro: vozes pouco ouvidas; Capítulo 5 Catadores de lixo e a questão racial no Brasil: um enfoque químico e social 
do lixo; Capítulo 6 - A fada madrinha da passabilidade - hormônios e o Ensino de Química; Capítulo 7 - Água, Direito Humano Fundamental: para que indivíduos em situação vulnerável se façam sujeitos de direitos; Capítulo 8-O caso das cerâmicas de Monte Carmelo: as interações no trabalho e na Química; Capítulo 9 - Agricultura e Ciclo do Nitrogênio: "fixando" o direito à terra

Observe que, mesmo partindo de um referencial teórico eurocêntrico, e não utilizando as categorias do grupo MCD, esta obra de Oliveira e Queiroz avança num comprometimento com o sul global, com a periferia e seus atingidos pelo processo de violência colonial.

No primeiro capítulo, remonta aos saberes ancestrais dos povos de terreiro para falar do orixá Exu, bem como de seus rituais e o uso das pimentas - gancho para abordar uma parte do conteúdo curricular previsto em química orgânica. Nesse sentido, é uma forma de descolonização do conhecimento.

No segundo capítulo, falam do preparo de sabões e detergentes. Ao invés de adotarem uma perspectiva prática, contextualizada e cotidianizada para o ensino do conteúdo - reações de saponificação -, escolhem partir dos sujeitos que vivem dessa prática: as mulheres quebradeiras de babaçu, que enfrentam cotidianamente o avanço da fronteira agrícola e a ganância capitalista sobre as terras, o que depreda a natureza e põe em risco o modo de vida tradicional dessas comunidades. Temos aqui tanto a valorização de saberes tradicionais e o combate ao epistemicídio, como também a valorização das lutas das mulheres do sul global e um comprometimento em enfrentar, numa tacada só, o racismo e o sexismo epistêmico.

No terceiro capítulo, tratam da questão da mineração e seus impactos socioambientais. Esse tema está diretamente relacionado com o modus operandi da modernidade e do capitalismo no continente latino-americano: a espoliação dos recursos naturais e, por meio disso, a separação entre homem (dominador) e natureza (dominada), o que violenta não só o modo de viver dos povos tradicionais, mas toda a vida no planeta, contaminando 
mananciais, desmatando, emitindo poluentes atmosféricos. Além disso, os impactos ambientais desde modo de se relacionar com a natureza são sentidos mais intensamente pelas populações marginalizadas - pobres, negros, indígenas, quilombolas -, o que constitui o racismo ambiental (CHAVIS, 1993 apud BARROZO; SANCHÉZ, p. 4, 2015). Questões similares de injustiça e racismo ambiental, frutos da lógica de espoliação e produção capitalista também são abordadas nos capítulos 5, 7, 8 e 9 .

No quarto capítulo, discute-se o apagamento feminino na história da ciência, o que pode ser estendido para todas as identidades que fogem do homem, branco, europeu. Gosfoguel (2016) aborda muito bem essa questão ao destrinchar que estrutura do conhecimento é pautada no racismo e no sexismo epistêmico - ou seja, no encobrimento dos saberes dos negros, dos indígenas e das mulheres.

O privilégio epistêmico dos homens ocidentais sobre o conhecimento produzido por outros corpos políticos e geopolíticas do conhecimento tem gerado não somente injustiça cognitiva, senão que tem sido um dos mecanismos usados para privilegiar projetos imperiais/coloniais/patriarcais no mundo. A inferiorização dos conhecimentos produzidos por homens e mulheres de todo o planeta (incluindo as mulheres ocidentais) tem dotado os homens ocidentais do privilégio epistêmico de definir o que é verdade, o que é a realidade e o que é melhor para os demais. Essa legitimidade e esse monopólio do conhecimento dos homens ocidentais tem gerado estruturas e instituições que produzem o racismo/sexismo epistêmico, desqualificando outros conhecimentos e outras vozes críticas frente aos projetos imperiais/coloniais/patriarcais que regem o sistema-mundo. (Grosfoguel, 2016, p.25)

O sexto capítulo traz um destaque para a Química dos hormônios e dialoga com o processo de passabilidade - a transformação dos aspectos fenotípicos que caracterizam gêneros. Nele as vozes de transexuais são 
ouvidas e problematizadas. Aqui temos a presença, mesmo que textual, de grupos marginalizados e não apenas uma teorização sobre eles.

Em termos metodológicos, nesta obra todos autores e autoras tiveram contato direto com os grupos sobre os quais escreviam, sendo parte deles ou investigando, através de entrevistas, por exemplo. $\mathrm{O}$ fato dos/as pesquisadores/as ouvirem e fazerem ouvir as vozes dos/as oprimidos/as através de suas intenções e práticas docentes é um avanço em relação aos outros dois livros analisados, que baseavam-se na discussão a partir de autores de referência que falavam sobre negrxs, LGBTs, mulheres... Isso dialoga com o apontado por Fleuri (2017), Miranda (2013), Valência (2015), Valla (1996) e tantos outros sobre a necessidade de se construir na e com a comunidade, com os/as oprimidos/as para então possibilitar a organização social para o enfrentamento e a superação das problemáticas sociais estruturantes de cada contexto e então alargar as fronteiras epistêmicas.

\section{Um caminho possivel}

Durante este texto, buscamos refletir se as propostas elaboradas por Oliveira e Queiroz (2013, 2015, 2017) acerca da Educação em Ciências e na perspectiva da Educação em Direitos Humanos dialoga com o campo dos estudos decoloniais. A partir das análises tecidas com base nos referenciais trazidos para esta conversa, concluímos que sim, este é um caminho possível.

Um aspecto importante e que nos proporcionou algumas reflexões sobre o trabalho foi o fato de que a opção pelos Direitos Humanos não surgiu como um estudo teórico, mas sim de uma necessidade prática e que posteriormente desencadeou estudos teóricos e, como consequência, fez um convite à reestruturação de práticas e pensamentos. Os subalternizados negros/as, população LGBT, a população campesina, os afetados por barragens, trabalhadores do Brasil, de maneira geral surgem para nós, professores/as de ciências a partir do chão da sala de aula, do contato com o povo, do diálogo com os outros. 
As obras dialogam com uma Educação em Direitos Humanos contrahegêmonica, combativa e posicionada politicamente a favor daqueles que foram subalternizados e historicamente marginalizados, sendo esses os herdeiros da violência colonial - não é por acaso que os pobres e desprivilegiados no Brasil são majoritariamente negros e índios - como já trazia a bandeira da Estação Primeira da Mangeira em seu emblemático desfile de 2019, que substituía o mote "ordem e progresso" por "índios, negros e pobres"; o nome disso é herança colonial.

Contudo, foi possível perceber que nem sempre os autores afrontam a colonialidade do saber, uma vez que as ciências centrais destas obras química, física e biologia - são base para a seleção de conteúdos conceituais pertinentes a serem ensinados. Os autores também não confrontam diretamente o modelo de educação escolar, e segundo Miranda (2013) esta seria uma das fronteiras a serem rompidas para uma prática decolonial. Tampouco confrontam explicitamente o sistema capitalista como o produtor e mantenetor de tais processos de violência colonial e desigualdades históricas.

Ainda assim, defendemos que a relação entre a Educação em Ciências na perspectiva da Educação em Direitos Humanos estabelece diálogos com o campo da decolonialidade. Isso porque os trabalhos desenvolvidos pelos autores analisados partem exatamente dos/as condenados/as da terra, dos/as excluídos/as e marginalizados/as do sistema - negros/as, mulheres, LGBTs, ribeirinhos, trabalhadores da mineração, fabricantes de telhas, quebradeiras de coco de babaçu, catadores de lixo, indígenas, etc. E talvez o mais interessante - ou o mais surpreendente - seja que o fazem a partir de áreas de conhecimento bastante endurecidas, as ciências da natureza, e ainda mais, buscando dialogar questões político-sociais com os conteúdos de química, física e biologia dos currículos escolares.

Ou seja, não se trata apenas de denúncia. Eles anunciam, artigo a artigo, maneiras outras e possíveis de humanizar o ensino de ciências, que, tendo em vista o supracitado, para nós também significa descolonizar o 
ensino de ciências - o processo no qual se abre caminho para que a decolonialidade flua até um dia chegarmos ao não-colonial, ou seja, superarmos a desumanização.

\section{Referências}

BARROZO, Luciana Aranda; SÁNCHEZ, Celso. Educação ambiental crítica, interculturalidade e justiça ambiental: entrelaçando possibilidades. VIII EPEA Encontro de Pesquisa em Educação Ambiental. Rio de Janeiro, 2015.

BRASIL. Ministério da Educação. Conselho Nacional de Educação. Resolução $\mathrm{n}^{0} 2$, Define as Diretrizes Curriculares Nacionais para a formação inicial em nível superior (cursos de licenciatura, cursos de formação pedagógica para graduados e cursos de segunda licenciatura) e para a formação continuada. 1 de julho de 2015.

. Secretaria Especial dos Direitos Humanos. Comitê Nacional de Educação em Direitos Humanos. Plano Nacional de Educação em Direitos Humanos. Brasília: 2003.

. Secretaria Especial dos Direitos Humanos. Plano Nacional de Educação em Direitos Humanos. Brasília: 2006.

Ministério da Educação. Conselho Nacional de Educação. Diretrizes Nacionais para a Educação em Direitos Humanos. Brasília: Diário Oficial da União: 30 de maio de 2012.

CANDAU, V. M.; PAULO, I. ANDRADE, M.; LUCINDA, M. C.; SACAVINO, S.; AMORIN, V. Educação em Direitos Humanos e Formação de professores. São Paulo, Editora Cortez, 2013, 232p.

DEMO, P. Introdução à metodologia da ciência. 2. ed. São Paulo: Atlas, 1985.

DUSSEL, Enrique. 1492 o encobrimento do outro: a origem do mito da modernidade. Tradução Jaime A. Clasen. Petrópolis: Vozes, 1993.

FANON, Frantz. Os condenados da terra. $2^{\text {a }}$ ed. Rio de Janeiro: Civilização Brasileira, 1979.

FLEURI, Reinaldo Matias. Aprender com os povos indígenas. In: Revista da Educação Pública, v.26, n.62/1, maio/ago. 2017.

GROSFOGUEL, Ramon. A estrutura do conhecimento nas universidades ocidentalizadas: racismo/sexismo epistêmico e os quatro epistemicídios do longo século XVI. In: Revista da Sociedade e do Estado, v. 15, n.1, p.25-49, jan/abril, 2016.

LOPES, Alice Casimiro. Os parâmetros curriculares nacionais para o ensino médio e a submissão ao mundo produtivo: o caso do conceito de contextualização. In: 
Educ. Soc., Campinas, vol. 23, n. 80, setembro/2002, p. 386-400. Disponível em: http://www.cedes.unicamp.br. Acesso em 20/05/2018.

MIGNOLO, Walter. Histórias locais/projetos globais: colonialidade, saberes subalternos e pensamento liminar. Belo Horizonte: Editora UFMG, 2003.

Desobediência epistêmica: a opção descolonial e o significado de identidade em política. Trad. Ângela Lopes Norte. Cadernos de Letras da UFF - Dossiê: Literatura, língua e identidade, n 34, p. 287-324, 2008.

- Colonialidade: o lado mais escuro da modernidade. Introdução de The darker side of western modernity: global futures, decolonial options (Mignolo, 2011). Trad. Marco Oliveira. RBCS, Vol. 32, n 94, junho, 2017.

MIRANDA, Cláudia. Currículos decoloniais e outras cartografias para a educação das relações étnico-raciais: desafios político-pedagógicos frente a lei $\mathrm{n}^{\circ}$ 10639/03. In: Revista da ABPN, v. 5, n. 11, jul/out 2013, p. 100-118.

MOREIRA, P. F. S. D.; RODRIGUES FILHO, G. F.; JACOBUCCI, D. F. C. A bioquímica do candomblé: possibilidades didáticas de aplicação da lei federal 10.639/03. Química Nova na Escola, v.33, p. 85-92, 2011.

QUIJANO, Anibal. Colonialidade do poder e classificação social. In: SANTOS, Boaventura de Sousa; MENESES, Maria Paula. (Org.). Epistemologias do Sul. São Paulo: Cortez, 2010.

OLIVEIRA, Roberto. Dalmo. V. L.; QUEIROZ, Glória. Regina. P. C. Educação em ciências e direitos humanos: Reflexão-ação em/para uma sociedade plural. Rio de Janeiro: Editora Multifoco, 2013.

- Olhares sobre a (in) diferença: formar-se professor de Ciências a partir de uma perspectiva de educação em direitos Humanos. São Paulo: Ed. Livraria da Física, 2015.

Tecendo diálogos sobre direitos humanos na educação em ciências. São Paulo: Ed. Livraria da Física, 2016.

Conteúdos cordiais: química humanizada para uma Escola sem Mordaça. São Paulo: Ed. Livraria da Física, 2017.

ONU. Declaração Universal dos Direitos Humanos. UNIC, Rio - Agosto 2009. Disponível em: https://nacoesunidas.org/wp-content/uploads/2018/10/DUDH.pdf

ORLANDI, Eni, P. Análise de discurso: principios e procedimentos. Campinas, Editora Pontes, 2010. 100p.

OCAÑA, Alexandre Ortiz. Decolonizar la educacion: pedagogia curriculo y didactica decoloniales. Editorial Académica Española, 2017. 
SACAVINO, S. Democracia e Educação na America Latina. Petrópolis: DP et alii/Novamérica, 2009.

SILVA, A. M.; TAVARES, C. A Educação em Direitos Humanos no Brasil: contexto, processo de desenvolvimento, conquistas e limites. Educação, Porto Alegre, v.36, n.1, p. 50-58, 2013.

TODOROV, Tzvetan. A conquista da América: a questão do outro. São Paulo: Martins Fontes, 2003.

TORRES, Nelson Maldonato. Del mito de la democracia racial a la descolonización del poder, del ser, $y$ del conocer. Disponível em: https://globalstudies.trinity.duke.edu/wp-content/themes/cgsh/ materials/events/DelMito .pdf. Acesso em: 12/05/2018.

WALSH, Catherine. Interculturalidad y (de)colonialidad: perspectivas críticas y políticas. In: Revista Visão Gloval, Joaçaba, v. 15. n. 1-2, jan/dez 2012, p. 61-74.

Pedagogias Decoloniales: prácticas insurgentes de resistir, (re)existir y (re)viver. Serie pensamento decolonial. San Pablo Etla, agosto, 2013.

Recebido em abril de 2019. Aprovado em novembro de 2019. 